\title{
A review of mathematical programming models of irrigation water values
}

\author{
BI Conradie ${ }^{1 *}$ and DL Hoag ${ }^{2}$ \\ ${ }^{1}$ School of Economics, University of Cape Town, Private Bag X1, Rondebosch 7701, South Africa \\ ${ }^{2}$ Department of Agriculture and Resource Economics, Colorado State University, Fort Collins Colorado 80523-1172, USA
}

\begin{abstract}
By introducing the user-pays principle into the irrigation water pricing debate, the 1998 National Water Act created a demand for models to measure willingness-to-pay for irrigation water. Water values are traditionally simulated with mathematical programming models. Models differ in their treatment of crops, irrigation options and water constraints, and other firm-level characteristics but they all use shadow prices as an indication of water value. The 17 models reviewed here, report average annual water values of between $\$ 0.0042 \cdot \mathrm{m}^{-3}$ and $\$ 0.1899 \cdot \mathrm{m}^{-3}$. Crops modelled influence water values, but there is no apparent relationship between objective function specification and average value. Nor does the number of irrigation options seem to influence water value either. The policy implication is that while similar models for the same region produce consistent estimates, each region requires its own model that has to be updated regularly.
\end{abstract}

Keywords: Q15, Q12, water value, irrigation, mathematical programming

\section{Introduction}

By raising the issue of full cost-recovery, the 1998 National Water Act made it clear that up to that point irrigation water was considerably subsidised in South Africa, and that price increases would be necessary to achieve optimal allocation. The Department of Water Affairs and Forestry (DWAF) responded immediately by doubling water rates in many cases, but it is unclear whether full cost-recovery would be feasible in the short term. While clear consensus exists about the conditions for allocative efficiency, as outlined by Sampath (1992), the international debate on the feasibility of full cost-recovery is far from over. The conclusion of this debate is an empirical issue; when the net present value of the total benefit of irrigation water is smaller than the net present value of total costs, full cost-recovery is impossible. When it is greater, full cost-recovery is feasible. One thus needs an accurate estimate of the demand for irrigation water to resolve the empirical issue. This creates a demand for models to measure willingness-to-pay for irrigation water. While isolated alternatives exist, mathematical programming is traditionally the tool of choice to simulate irrigation water values (Gibbons, 1986). This review discusses the theoretical framework on which this class of model relies and then describes 17 models reported over the past 20 years before concluding on the potential usefulness of mathematical programming models to resolve the empirical cost-recovery debate.

\section{Theoretical framework}

Ricardian rents provide the theoretical framework for residual imputation with mathematical programming models. Under per-

\footnotetext{
* To whom all correspondence should be addressed.

용 +2721 650-2731; fax: +2721 650-2854;

e-mail: bconradi@commerce.uct.ac.za

Received 27 May 2003; accepted in revised form 15 March 2004.
}

fect competition, when the firm is a price-taker in factor and product markets, payments to all variable factors of production are exactly equal to total revenue, making economic profits zero. Here the firm is a farm. The theory is simple. Economic profits, if any exist, are returns to fixed factors of production, potentially including irrigation water.

By this logic static and dynamic linear and non-linear programming models have been used not only to simulate total benefits of irrigation water, but also to derive demand functions for it. Models are set up to maximise profit subject to, amongst others, water constraints, which are then parametrically tightened to derive a schedule of shadow prices. A linear programming shadow price is the marginal contribution to the objective function (profit) attributable to an additional unit of the binding constraint (Beneke and Winterboer, 1973). The shadow price of water directly estimates the marginal value product of water; the demand for the resource is simply the quantity constraint as a function of the shadow price and total value is the integral of this function. To be an accurate estimate of water value, water must be the only fixed factor in the model and the input-output coefficients must be correct.

The vast majority of irrigation water value models use residual imputation. Even Howe (1985), who based his demand curve for water on the gross margin of individual crops, uses the idea that residual profits indicate the value of water. There are three alternatives to residual imputation. The first estimates a crop-water production function from field trials and then scales this physical production function by the price of the product (Colby, 1989; Penzhorn and Marais, 1998). The second approach is to estimate a demand function directly from water price data. Griffin and Perry (1985) presented an econometric model using panel data of irrigation prices in Texas. The third approach is to use Hedonic pricing methods to measure the contribution of water value to farm prices. Torell et al. (1990) estimated water in the Ogallala Aquifer to be worth between $\$ 0.0009 \cdot \mathrm{m}^{-3} \cdot \mathrm{a}^{-1}$ and $\$ 0.0077 \cdot \mathrm{m}^{-3} \cdot \mathrm{a}^{-1}$. Faux and Perry (1999) estimated the water value in Malheur County, Oregon, to be between $\$ 0.0073 \cdot \mathrm{m}^{-3} \cdot \mathrm{a}^{-1}$ and $\$ 0.0357 \cdot \mathrm{m}^{-3} \cdot \mathrm{a}^{-1}$. 


\section{Discussion of mathematical programming models}

Since the accuracy of water value estimates depends on how realistic a model is, models relying on extensive surveys should produce better results than models using smaller or more general datasets. Incorporating a large percentage of observed crops, soil variances, accurate supply constraints and a comprehensive range of irrigation substitution possibilities should also improve estimates. Not all models achieve everything. The literature separates them into three main strands; optimal allocation models, water demand models that estimate the value of water under various scenarios, and other models that incorporate aspects that may be included in future water value models.

\section{Optimal allocation models}

Timing of irrigation events matters almost as much as the size of the application. Some mathematical programming models calculate benefits foregone from not scheduling optimally during the course of an irrigation season. Flinn and Musgrave (1967) specified yield as a function of cumulative irrigation. McGuckin et al. (1987) optimised irrigation scheduling using a random timeframe based on heat units instead of chronological time. The dynamic programming model accounts for stochastic weather and soil water processes and expresses water stress as a proportion of "full irrigation" yield. Activities consist of combinations of three crops (maize, sorghum and cotton) and two irrigation systems (furrow and sprinkler). Optimal scheduling raised profits by $5 \%$. Average water values are presented in Table 1.

In another dynamic programming model, Bryant et al. (1993) chose to irrigate or not irrigate maize and sorghum with a centrepivot system in 16 different growth stages. A fixed volume of water is applied during each irrigation event. The model also includes dryland production and the option to abandon crops during droughts. The EPIC crop simulator calculates maize and sorghum yields for each irrigation strategy. The economic model subtracts a variable irrigation cost and harvesting and handling costs from actual commodity revenues to find net revenue. The cost of working capital is included at $12 \%$ per year. The model was calibrated with data provided by the Texas Extension Service. Results indicate that it is optimal to irrigate the driest field any time unless maize is below wilting point, in which case maize gets priority over sorghum. Irrigation scheduling leads to a marginal $\left(\$ 1.25\right.$ to $\left.\$ 3.50 \cdot \mathrm{ac}^{-1}\right)$ improvement in profit. Average water values are not reported.

Where farms have access to more than one source of water, for example fresh surface water and saline groundwater, the scheduling decision involves selecting water from the cheapest source, adjusted for the salt sensitivity by growth stage. Three examples of this approach are given in Cornforth and Lacewell (1982), Lefkoff and Gorelick (1990) and Afzal et al. (1992). All three models

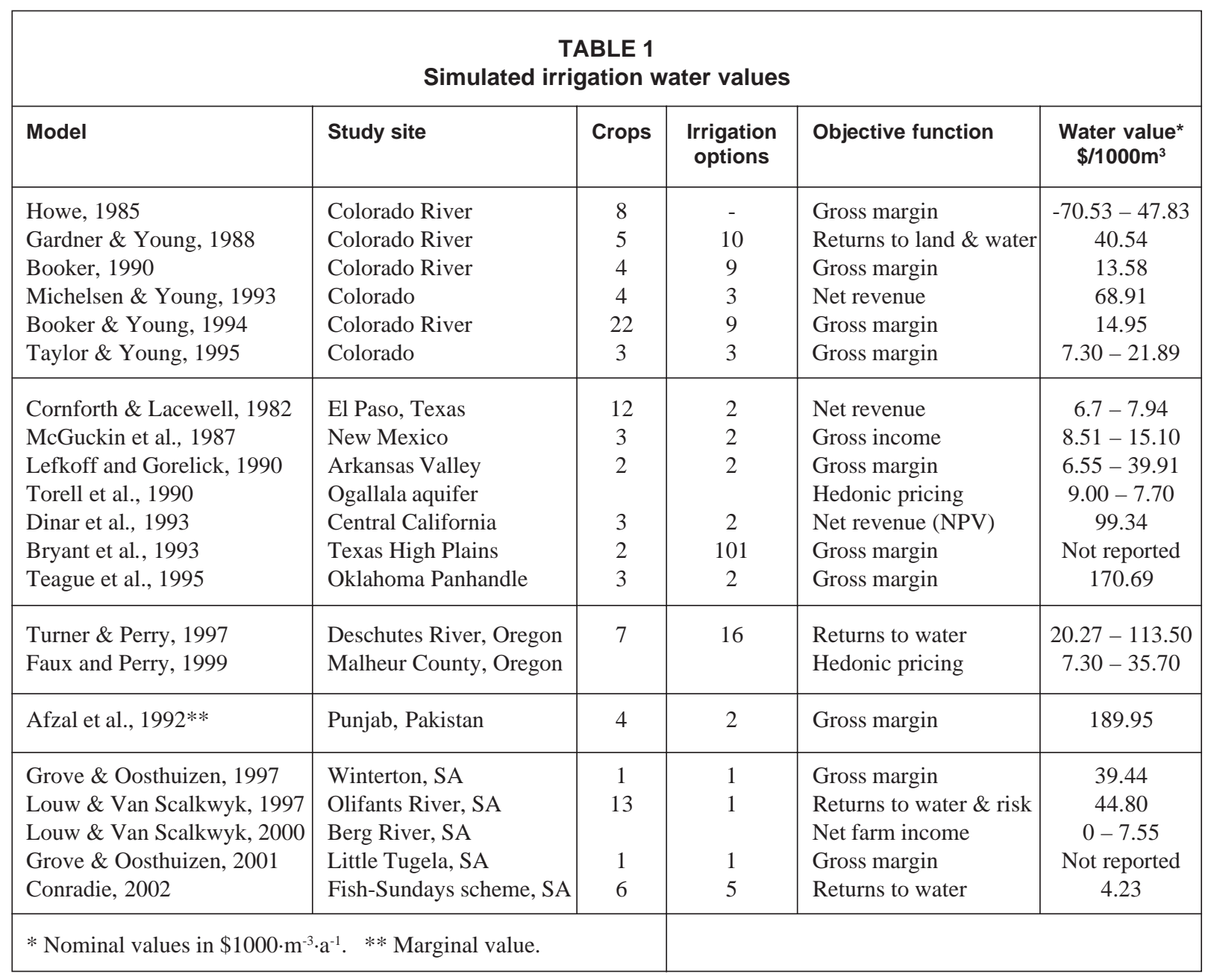


optimise with static linear programming. Cornforth and Lacewell (1982) found that scheduling only improves total water value by $3 \%$, while Lefkoff and Gorelick (1990) recorded a 38\% improvement and Afzal et al. (1992) noted a $65 \%$ gain by omitting four out of the last five irrigation events for cotton.

In the Cornforth and Lacewell's (1982) model successive periods took a block diagonal design. Net revenue is maximised over several years across ten annual crops as well as pecan trees and lucerne for six soils and two water sources. Afzal et al. (1992) maximised net revenue across four crops (maize, wheat, barley and cotton), one irrigation technology and two water sources. The model incorporates a standard Doornbosh-Kassam salinity damage function and models deficit irrigation as missing an irrigation event. Lefkoff and Gorelick (1990) used an existing hydrological model of their study area to track water percolation and salt loading. The objective function maximises firm-level profits across two crops (maize and lucerne) and two water sources subject to an area constraint, a surface water constraint and a pumping constraint. The cost for using unlimited groundwater is the salinity damage incurred.

Grove and Oosthuizen (1997) investigated the effects of deficit irrigation and improving irrigation systems efficiency. ACRU was used to model the hydrology, the indicator crop was wheat and the system technology is not reported. The objective function maximises net income in a chance-constrained linear programming model. Water stress is modelled as yield reduction of the DoornbosKassam type. A maximum water reduction of $20 \%$ was allowed. Supply conditions are varied parametrically and return flows are calculated ex-post, by assuming that roughly half of non-consumptive use can be used downstream similar to Booker's (1990) specification. This paper reports a base value of returns to water and other fixed factors of $\$ 0.0394 \cdot \mathrm{m}^{-3} \cdot \mathrm{a}^{-1}$. Improving systems efficiency from $67 \%$ to $75 \%$ increases gross margin by $\$ 0.0006 \cdot \mathrm{m}^{-3} \cdot \mathrm{a}^{-1}$. This is interpreted as the maximum willingness-to-pay to improve systems efficiency.

\section{Water demand models}

This strand of the literature includes models used to derive water demand functions. Two examples from the local literature are notable insofar as they accurately represent observed crops. Louw and Van Schalkwyk (1997) estimated water demand for the Olifants River in the Western Cape that accounts for $95 \%$ of the irrigated area in the basin. Conradie (2002) modelled 50 000ha of fodder crops and citrus orchards on the Fish-Sundays transfer scheme in the Eastern Cape. Conradie (2002) explicitly modelled links with extensive sheep and goat farming in areas adjacent to the river. Louw and Van Schalkwyk (1997) reported an average water value of $\$ 0.0448 \cdot \mathrm{m}^{-3} \cdot \mathrm{a}^{-1}$ while Conradie (2002) found an average value of $\$ 0.0042 \cdot \mathrm{m}^{-3} \cdot \mathrm{a}^{-1}$ overall and $\$ 0.0249 \cdot \mathrm{m}^{-3} \cdot \mathrm{a}^{-1}$ for citrus farms.

Louw and Van Schalkwyk (1997) maximised the present value of returns to risk and water while Conradie (2002) only used a single period static model but explicitly modelled returns to risk with a MOTAD specification. Both models account for overhead costs (at different rates for irrigated and dry-land production) including household living expenses, water rates and interest. Thirteen crops (citrus, wine grapes, table grapes, lucerne, potatoes, tomatoes, onions, watermelon, squash, green beans, sweet potatoes, sweet corn and pumpkin) were modelled for the existing irrigation technology in Louw and Van Schalkwyk (1997). COMBUD data were used. The ratio of bearing to non-bearing orchards is specified exogenously to ensure orchard replacement. Conradie (2002) used the same approach for citrus and lucerne, but modelled various typical farms by varying the ratio of bearing to non-bearing orchards. Conradie (2002) modelled six crops (lucerne, maize, dry beans, potatoes, pasture and citrus), four livestock activities (wool sheep, angoras, dairy cows and ostriches) and five irrigation systems (flood, laser-levelled flood, sprinkler, centre pivot, micro jets) on 16 typical farms. The 16 typical farms were identified from a $25 \%$ sample of all irrigators on the scheme and crop and livestock data were collected in interviews with farmers and extension specialists. Louw and Van Schalkwyk (1997) used an exogenous crop constraint to calibrate their model.

Gardner and Young (1988) designed one of a series of linear programming models to test policy options for the Colorado River. The model compares the efficiency and cost effectiveness of irrigation equipment subsidies to effluent taxes and price increases for irrigation water. The model maximises net revenue across five crops (lucerne, barley, maize, pasture and dry beans) and four irrigation technologies (siphon tubes, gated pipes, ported ditch and 'cablegation') used at different labour intensities with and without lined ditches. Land retirement is also an option. Crop mix is exogenously constrained to the long-term average plus and minus one standard deviation. Parameters for crop activities come from extension service reports while irrigation extension specialists supplied irrigation parameters. The average baseline value of irrigation water is $\$ 0.0405 \cdot \mathrm{m}^{-3} \cdot \mathrm{a}^{-1}$. The most cost-effective way to reduce saline return-flows is by subsidising irrigation hardware. Salt loads can be reduced by about $10 \%$ by a fourfold price increase $\left(\$ 4.49 \cdot \mathrm{t}^{-1}\right.$ salt removed), by taxing salt directly $\left(\$ 1.10 \cdot \mathrm{t}^{-1}\right.$ salt removed) or by subsidising irrigation hardware $\left(\$ 0.40 \cdot \mathrm{t}^{-1}\right.$ salt removed).

Booker (1990) updated Gardner and Young (1988) to form the irrigation component of a basin-wide allocation model of the Colorado River. Booker (1990) maximised net revenue across four crops (lucerne, maize, pasture and dry beans) for nine irrigation strategies. It is assumed that lucerne fields are replanted every sixth year and crop mix is specified in an exogenous constraint. Perennial fruit is mentioned but not modelled. Booker (1990) argued that since fruit generate higher returns to water than field crops, model results represent a lower bound of agricultural values. A simple salinity constraint, in the form of a salt balance derived from returnflows, allowed Booker (1990) to trade off upstream irrigation benefits against downstream salinity damages. Return-flows are the difference between water applied and average consumptive use for the area. Booker (1990) estimated that the average value of the current allocation is $\$ 0.0136 \cdot \mathrm{m}^{-3} \cdot \mathrm{a}^{-1}$. A $20 \%$ reduction of the allocation increases the marginal water value to $\$ 0.0523 \cdot \mathrm{m}^{-3} \cdot \mathrm{a}^{-1}$. The marginal cost of salinity is also reported.

The Michelsen and Young (1993) model maximises net revenue and accounts for four crops (maize, lucerne, dry beans and barley) and two irrigation systems (furrow and flood). The model also incorporates dry-land lucerne. The typical exogenous range on crop mix is used in this case and the model incorporates a stochastic river flow component to simulate droughts. Results show an offer price of $\$ 0.0689 \cdot \mathrm{m}^{-3} \cdot \mathrm{a}^{-1}$, clearly suggesting gains from trade with Denver where additional supplies are estimated to cost $\$ 3.24 \cdot \mathrm{m}^{-3} \cdot \mathrm{a}^{-1}$.

In a similar paper Louw and Van Schalkwyk (2000) analysed the effect of potential water markets in the Berg River basin of the Western Cape, South Africa. The model maximises social welfare (consumer and producer surplus) across six production districts as well as residential and industrial use. It includes perennial and annual crops, but does not say which. The irrigation options are also not reported. In the base case current irrigation water values vary between zero and $\$ 0.00045 \cdot \mathrm{m}^{-3} \cdot \mathrm{a}^{-1}$ with a median value of zero. When irrigators are permitted to sell water at $\$ 0.006 \cdot \mathrm{m}^{-3} \cdot \mathrm{a}^{-1}$, 
the median residual value increases to $\$ 0.00137 \cdot \mathrm{m}^{-3} \cdot \mathrm{a}^{-1}$. A $20 \%$ reduction in available water (or a $20 \%$ increase in urban demand) leaves irrigation water values unaffected at sale prices of $\$ 0.003 \cdot \mathrm{m}^{-3} \cdot \mathrm{a}^{-1}$.

Booker and Young (1994) presented a basin-wide analysis for the Colorado River that maximises net economic surplus across all uses. The model includes mass balance constraints of water and soluble salts, using Booker's (1990) return-flow specification. Municipal demand and inter-basin transfers are assumed fixed, and hydropower benefits are modelled as marginal costs avoided. Irrigation benefit functions, estimated from programming results, calculate profits as a function of the water constraint. Irrigation demand in the lower basin represents 13 crops on two soil types for high (1 $\left.100 \mathrm{mg} \cdot \ell^{-1}\right)$ and low $\left(800 \mathrm{mg} \cdot \ell^{-1}\right)$ salinity. Four crops and nine irrigation strategies are modelled in the upper basin. The results for six institutional scenarios involving various marketing arrangements are presented. Municipal demand in California values water at $\$ 0.2432 \cdot \mathrm{m}^{-3} \cdot \mathrm{a}^{-1}$ while irrigation generates values of $\$ 0.0146 \cdot \mathrm{m}^{-3} \cdot \mathrm{a}^{-1}$. This demand can be met from Californian irrigation (intra-state trade) or Colorado irrigation (inter-state trade). Redistribution within California and across states increases total benefit as expected. The total loss to agriculture is much lower in the second case, because removing a structural transfer constraint allows low value irrigation upstream to be accessed first.

Turner and Perry (1997) examined willingness to sell irrigation water with a linear programming model that accounts for uncertain water supplies by defining the objective function as a function of probable crop yield. Yield, in turn, is a quadratic function of available water. The model incorporates seven crops (irrigated pasture and grass hay, lucerne, wheat, peppermint oil, carrot seed, garlic seed and bluegrass seed) and sixteen irrigation options ranging from basic flood technology to centre pivots. Each technology is modelled with and without irrigation scheduling which is assumed to improve systems efficiency by $10 \%$ and reduce deep percolation by $5 \%$. The model isolates water values as the residual profit after all other fixed factors have been compensated at opportunity cost. Risk is treated as a firm-level fixed cost, and rental values in the area were used as a proxy for land rents. Here, fixed costs are not subtracted as a flat rate per hectare but expressed as a fraction of gross income, allowing profit increases or decreases to be spread equally across all fixed factors and not accrue to water only as in the case of the Louw and Van Schalkwyk (1997) or Conradie (2002) models. The average value of water derived from fodder crop production is estimated to be $\$ 0.0203 \cdot \mathrm{m}^{-3} \cdot \mathrm{a}^{-1}$. About a third of current allocation is used to irrigate fodder crops. The highest value crop is vegetable seed, which generates a water value of $\$ 0.1135 \cdot \mathrm{m}^{-3} \cdot \mathrm{a}^{-1}$.

Taylor and Young (1995) introduced stochastic weather into the standard valuation model, showing that uncertainty about weather increases water values in a dry year and decreases water values in a wet year compared to average evaporation figures. In the standard model the marginal value of water at the mean diversion level is estimated to be $\$ 0.0219 \cdot \mathrm{m}^{-3} \cdot \mathrm{a}^{-1}$ in dry years and $\$ 0.0073 \cdot \mathrm{m}$ ${ }^{3} \cdot \mathrm{a}^{-1}$ in wet years. Uncertainty about weather reduces the marginal value of water in a wet year to zero, and increases the value of water in a dry year to $\$ 0.0389 \cdot \mathrm{m}^{-3} \cdot \mathrm{a}^{-1}$. Taylor and Young (1995) modelled the planting decision in the presence of an uncertain water supply. Crop decisions, the control variables, are revised at various production stages. The model maximises expected regional income across three crops (maize, lucerne and sorghum), four soil types, three irrigation strategies and two water supply scenarios. As in the case of Afzal et al. (1992) deficit irrigation is defined as omitting an irrigation event, rather than applying smaller volumes. Crop rota- tion is an exogenous constraint. The model is calibrated to observed crop distribution.

\section{Related models}

A small number of alternative specifications need to be noted. The model developed by Mallawaarachchi et al. (1992) is interesting for two reasons. First, it contributes to the tiny literature on the decision to invest in water saving irrigation technologies for perennial crops. Secondly, it models the water constraint as a water purchase activity rather than the usual resource constraint. The model maximises terminal value of a 20 -year investment period, which is equivalent to maximising net present value (Mallawaarachchi et al., 1992). Results show that the decision to switch to drip irrigation is taken to avoid water cost or to expand orchards.

Dinar et al. (1993) refines the standard model by using lysimeter field data to derive firm-level production functions instead using a crop simulation model to derive the deficit irrigation function. The model incorporates multiple sources and qualities of water and permits a water marketing activity. Three crops are included (wheat, sorghum and irrigated pasture) and two irrigation technologies are modelled. Baseline results indicate an average water value of $\$ 0.0993 \cdot \mathrm{m}^{-3} \cdot \mathrm{a}^{-1}$. The policy options considered are water taxes, effluent taxes and technology subsidies. Two results are particularly interesting. First, a subsidy of $60 \%$ of capital cost is necessary to make farmers indifferent to deciding between flood and sprinkler technology. Secondly, while Pigovian taxes are more effective and cost-efficient than targeting irrigation water, the difference is negligible, suggesting that the more straightforward procedure is the appropriate policy intervention.

Teague et al. (1997) used target MOTAD to examine various levels of compliance with nitrate and pesticide regulation. The standard target MOTAD formulation sets a target income and varies a risk aversion coefficient parametrically. In this model a compliance coefficient is varied around a target level of nitrate or pesticide leaching. This environmental risk aversion parameter is interpreted as "the acceptable level of compliance with the target", and the magnitude of the coefficient indicates how much more pesticide or nitrate leaching than the specified target a farm produces. The advantage of this formulation is that it allows a nonlinear leaching function. The model includes three crops (maize, wheat, and sorghum) in various rotations on two soil types (clay loam and sandy loam) allowing three kinds of irrigation (furrow, centre pivot and dry-land). The model also includes a significant dry-land component. Results indicate that the base value of water is $\$ 0.1707 \cdot \mathrm{m}^{-3} \cdot \mathrm{a}^{-1}$.

Onal et al. (1998) modelled the water quality of runoff from arable land. The idea to limit the variability of economic loss across farmers, so that the cost of a given policy is equitably distributed across participants, is a useful way to introduce equity in water value models. An equal sharing of losses is defined as the (perfectly) equitable solution while zero equity is defined as the case where a single person bears all the costs and everybody else continues as before. The model is a chanceconstrained programming model that maximises a margin above certain variable costs subject to the normal constraints. It includes a stochastic variable representing atrazine leaching to a nearby reservoir.

Grove and Oosthuizen (2001) modelled supply conditions in the Little Tugela basin as shares of available streamflow rather than quantities of water. The model provides for three water categories, namely diversions, return-flows and water remaining in-stream due to selling water upstream. It integrates the ACRU hydrology 
model into a mixed integer non-linear programming model. Results indicate that unconstrained water markets will improve gross margin by $6 \%$, but that they will cause streamflow externalities as identified by Huffaker and Whittlesey (1995). If water rights are specified as consumptive use quantities, and trade is permitted, the benefit of trade is even smaller.

Berger (2001) emphasised the spatial heterogeneity of farming, an idea that Conradie (2002) captures by aggregating regional demand from 16 typical farms. Berger (2001) defined firm-level economic constraints such as farm size, soil type, water availability, interest rates paid, transport costs and so on. The model also assigns an adopter category to each farmer and then internalises the technology adoption process through common pools of information that result from the actions of innovators. Land and water markets and irrigation water return flows further refine spatial interactions in a regional model. The model output is a cumulative frequency of adoption of various technological innovations that recognise transaction costs explicitly and does not calculate water value as such.

\section{Discussion and conclusion}

The water values in Table 1 cover a broad range that is partly due to model specification. The difference in average water values between regions is not surprising. For example, there is no reason to be alarmed by the discrepancy in Conradie (2002) and Louw and Van Schalkwyk (1997). Willingness-to-pay for irrigation water is determined jointly by product price and the marginal productivity of irrigation. Location as a proxy for, amongst others, climate (which limits crop choice) captures the marginal product of irrigation. The value of $\$ 0.00423 \cdot \mathrm{m}^{-3} \cdot \mathrm{a}^{-1}$ for the Eastern Cape simply indicates a different crop mix than observed in the Western Cape where average water value is estimated to be $\$ 0.04480 \cdot \mathrm{m}^{-3} \cdot \mathrm{a}^{-1}$.

One would even expect differences over time for the same location since product prices may change. The upper basin of the Colorado River is perhaps the most intensively researched irrigation system in the world when it comes to simulation models of water value. Barring the Howe (1985) model, which considers individual crops including fodder crops that do not have a formal market, the annual value of irrigation water per thousand cubic meters is estimated to be between $\$ 7.30$ and $\$ 68.91$. The median value of $\$ 14.95$ indicates that when using similar methods for a given location, resulting values are tightly grouped.

The implication for policy makers is that in order to calculate willingness-to-pay for irrigation, each region needs its own simulation model that has to be updated regularly. A far more serious concern is the nature of the data used to populate the models. Almost all models rely on gross margin activity budgets compiled by extension services. Activity budgets are associated with typical farms, while it is well-known that farms are seldom homogeneous in a region. A comprehensive set of enterprise budgets is an integral part of any current model of water value in order to derive reasonably accurate estimates of willingness-to-pay for water.

\section{Acknowledgements}

The authors gratefully acknowledge financial assistance from the Water Research Commission.

\section{References}

AFZAL J, NOBLE DH and WEATHERHEAD KE (1992) Optimization model for alternative use of different quality irrigation waters. J. Irrig. Drain. Eng. 118 (2) 218-228.
BENEKE RR and WINTERBOER R (1973) Linear Programming Applications to Agriculture. Iowa State University Press, AMES.

BERGER T (2001) Agent-based spatial models applied to agriculture: A simulation tool for technology diffusion, resource use changes and policy analysis. Agric. Econ. 25 (2-3) 245-260.

BOOKER JF (1990) Economic Allocation of Colorado River Water: Integrating Quantity, Quality, and Instream Use Values. Unpublished $\mathrm{Ph}$.D. dissertation, Department of Agricultural and Resource Economics, CSU, Fort Collins.

BOOKER JF and YOUNG RA (1994) Modeling intrastate and interstate markets for Colorado River water resources. J. Environ. Econ. Manage. 26 66-87.

BRYANT KJ, MJELDE JW and LACEWELL RD (1993) An intraseasonal dynamic optimisation model to allocate irrigation water between crops. Amer. J. Agric. Econ. 75 1021-1029.

COLBY BG (1989) Estimating the value of water in alternative uses. Nat. Resour. J. 29 (2) 511-527.

CONRADIE BI (2002) The Value of Water in the Fish-Sundays Scheme of the Eastern Cape. WRC report 987/1/02. Water Research Commission, Pretoria.

CORNFORTH, GC and LACEWELL RD (1982) Farmer storage of irrigation water in federal projects. Western J. Agric. Econ. 7 227-238.

DINAR A, AILLERY MP and MOORE MR (1993) A dynamic model of soil salinity and drainage generation in irrigated agriculture: A framework for policy analysis. Water Resour. Res. 29 (6) 1527-1536.

FAUX J and PERRY GM (1999) Estimating irrigation water value using hedonic price analysis: A case study in Malheur county, Oregon. Land Econ. 75 (3) 440-452.

FLINN JC and MUSGRAVE WF (1967) Development and analysis of input-output relations for irrigation water. Austr. J. Agric. Econ. 11 (1) $1-19$.

GARDNER RL and YOUNG RA (1988) Assessing strategies for control of irrigation-induced salinity in the upper Colorado River basin. Am. J. Agric. Econ. 70 37-49.

GIBBONS D (1986) The Economic Value of Water. Resources for the Future. Publisher: Resources for the Future, Washington.

GRIFFIN RC AND PERRY GM (1985) Volumetric pricing of agricultural water supplies: A case study. Water Resour. Res. 21(7) 944-950.

GROVE B and OOSTHUIZEN LK (1997) 'n Ekonomiese evaluering van tekortbesproeiing en verhoogde watertoedieningsdoeltreffendheid op landbouwatergebruik. Agrekon 36 (4) 561-572.

GROVE B and OOSTHUIZEN LK (2001) Modelling water allocation problems at catchment level: The case of water markets with return flow externalities. Agrekon 40 (4) 770-779.

HUFFAKER RG and WHITTLESEY NK (1995) Agricultural water conservation legislation: Will it save water? Choices (4th quarter).

HOWE CW (1985) Economic, legal and hydrologic dimensions of potential interstate water markets. Am. J. Agric. Econ. 67 1226-1230.

LEFKOFF LJ and GORELICK SM (1990) Simulating physical processes and economic behavior in saline, irrigated agriculture: Model development. Water Resour. Res. 26 (7) 1359-1369.

LOUW DB and VAN SCHALKWYK HD (1997) The true value of irrigation water in the Olifants River basin: Western Cape. Agrekon 36 (4) $551-560$.

LOUW DB and VAN SCHALKWYK HD (2000) Water markets an alternative for central water allocation. Agrekon 39 (4) 484-494.

MALLAWAARACHCHIT, HALL N and PHILLIPS B (1992) Investment in water saving technology on horticultural farms. Rev. Mark. Agric. Econ. 62 (2) 191-204.

MICHELSEN AM and YOUNG RA (1993) Optioning agricultural water rights for urban water supplied during drought. Am. J. Agric Econ. $\mathbf{7 5}$ 1010-1020.

ONAL R, ALGOZIN KA, ISIK M and HORNBAKER RH (1998) Economically efficient watershed management with environmental impact and income distribution goals. J. Environ. Manage. 53 (3) 241-253.

PENZHORN N and MARAIS D (1998) Deficit irrigation has financial benefits. Farmers Weekly September 18 26-28.

SAMPATH RK (1992) Issues in irrigation pricing in developing countries. World Dev. 20 (7) 967-977. 
TAYLOR RG and YOUNG RA (1995) Rural-to-urban transfers: Measuring direct foregone benefits of irrigation water under uncertain water supplies. J. Agric. Res. Econ. 20 (2) 247-262.

TEAGUE ML, BERNARDO JD and MAPP HP (1995) Farm-level economic analysis incorporating stochastic environmental risk assessment. Am. J. Agric. Econ.77 8-19.
TORELL LA, LIBBEN JD and MILLER MD (1990) The market value of water in the Ogallala aquifer. Land Econ. 66 (2) 163-75.

TURNER B and PERRY GM (1997) Agriculture to instream water transfers under uncertain water availability: A case study of the Deschutes River, Oregon. J. Agric. Resour. Econ. 22 (2) 208-221. 